\title{
Some new generalized retarded nonlinear integral inequalities with iterated integrals and their applications
}

Wu-Sheng Wang*

\section{"Correspondence:} wang4896@126.com

Department of Mathematics, Hechi University, Yizhou, Guangxi 546300 P.R. China

\begin{abstract}
Some new generalized retarded nonlinear integral inequalities with iterated integrals are discussed and upper bound estimations of unknown functions are given by analysis technique. These estimations can be used as tools in the study of differential-integral equations with the initial conditions.
\end{abstract}

MSC: 26D10; 26D15; 26D20; 34A12; 34A40

Keywords: integral inequality; iterated integrals; analysis technique; retarded differential-integral equation; estimation

\section{Introduction}

Gronwall-Bellman inequalities [1,2] can be used as important tools in the study of existence, uniqueness, boundedness, stability and other qualitative properties of solutions of differential equations and integral equations. There can be found a lot of generalizations of Gronwall-Bellman inequalities in various cases from literature (e.g., [3-15]).

Agarwal et al. [5] studied the inequality

$$
u(t) \leq a(t)+\sum_{i=1}^{n} \int_{b_{i}\left(t_{0}\right)}^{b_{i}(t)} g_{i}(t, s) w_{i}(u(s)) d s, \quad t_{0} \leq t<t_{1} .
$$

Agarwal et al. [6] obtained the explicit bound to the unknown function of the following retarded integral inequality:

$$
\varphi(u(t)) \leq c+\sum_{i=1}^{n} \int_{\alpha_{i}\left(t_{0}\right)}^{\alpha_{i}(t)} u^{q}(s)\left[f_{i}(s) \varphi_{1}(u(s))+g_{i}(s) \varphi_{2}(\log (u(s)))\right] d s .
$$

In 2011, Abdeldaim and Yakout [4] studied the following integral inequalities:

$$
\begin{aligned}
& u(t) \leq u_{0}+\int_{0}^{t}(f(s) u(s)+q(s)) d s+\int_{0}^{t} f(s) u(s)\left[u(s)+\int_{0}^{s} g(\lambda) u(\lambda) d \lambda\right] d s, \\
& u(t) \leq u_{0}+\int_{0}^{t} f(s) u(s)\left[u(s)+\int_{0}^{s} g(\lambda) u(\lambda) d \lambda\right]^{p} d s .
\end{aligned}
$$

However, the bound given on such an inequality in [4] is not directly applicable in the study of certain retarded nonlinear differential and integral equations. It is desirable to

(C) 2012 Wang; licensee Springer. This is an Open Access article distributed under the terms of the Creative Commons Attribution License (http://creativecommons.org/licenses/by/2.0), which permits unrestricted use, distribution, and reproduction in any medium, provided the original work is properly cited. 
establish new inequalities of the above type, which can be used more effectively in the study of certain classes of retarded nonlinear differential and integral equations.

In this paper, we discuss some new retarded nonlinear integral inequalities with iterated integrals

$$
\begin{aligned}
u(t) \leq & u_{0}+\int_{0}^{\alpha(t)}(f(s) u(s)+q(s)) d s+\int_{0}^{\alpha(t)} f(s) u(s)\left[u(s)+\int_{0}^{s} g(\lambda) u(\lambda) d \lambda\right] d s, \\
u(t) \leq & u_{0}+\int_{0}^{\alpha(t)}(f(s) \varphi(u(s))+q(s)) d s \\
& +\int_{0}^{\alpha(t)} f(s) \varphi(u(s))\left[u(s)+\int_{0}^{s} g(\lambda) u(\lambda) d \lambda\right] d s, \\
u(t) \leq & u_{0}+\int_{0}^{\alpha(t)} f(s) u(s)\left[u(s)+\int_{0}^{s} g(\lambda) u(\lambda) d \lambda\right]^{p} d s, \\
u(t) \leq & u_{0}+\int_{0}^{\alpha(t)} f(s) \phi_{1}(u(s))\left[u(s)+\int_{0}^{s} g(\lambda) \phi_{2}(u(\lambda)) d \lambda\right]^{p} d s,
\end{aligned}
$$

where $u_{0}$ is a positive constant, and give upper bound estimation of the unknown function by integral inequality technique. Furthermore, we apply our result to differential-integral equations for estimation.

\section{Main result}

In this section, we discuss some retarded integral inequalities with iterated integrals. Throughout this paper, let $I=[0, \infty)$.

Lemma 1 (Abdeldaim and Yakout [4]) We assume that $u(t), f(t)$ and $g(t)$ are nonnegative real-valued continuous functions defined on $I=[0, \infty)$ and satisfy the inequality

$$
u(t) \leq u_{0}+\int_{0}^{t} f(s) u(s)\left[u(s)+\int_{0}^{s} g(\lambda) u(\lambda) d \lambda\right]^{p} d s
$$

for all $t \in I$, where $u_{0}$ and $p$ are positive constants. Then

$$
u(t) \leq u_{0} \exp \left(\int_{0}^{t} f(s) B_{1}(s)\right) d s, \quad \forall t \in I
$$

where

$$
B_{1}(t)=\frac{u_{0}^{p} \exp \left(p \int_{0}^{t} g(s) d s\right)}{1-p u_{0}^{p} \int_{0}^{t} f(s) \exp \left(p \int_{0}^{s} g(\tau) d \tau\right) d s},
$$

such that $p u_{0}^{p} \int_{0}^{t} f(s) \exp \left(p \int_{0}^{s} g(\tau) d \tau\right) d s \leq 1$ for all $t \in I$.

Lemma 2 (Abdeldaim and Yakout [4]) We assume that $u(t), f(t)$ and $g(t)$ are nonnegative real-valued continuous functions defined on $I=[0, \infty)$ and satisfy the inequality

$$
u(t) \leq u_{0}+\int_{0}^{t}(f(s) u(s)+q(s)) d s+\int_{0}^{t} f(s) u(s)\left[u(s)+\int_{0}^{s} g(\lambda) u(\lambda) d \lambda\right] d s,
$$


for all $t \in I$, where $u_{0}$ is a positive constant. Then

$$
u(t) \leq\left(u_{0}+\int_{0}^{t} q(s) \exp (-A(s)) d s\right) \exp (A(t)), \quad \forall t \in I,
$$

where $A(t)=\int_{0}^{t}\left(f(s)+f(s) Q_{1}(s)\right) d s$, and

$$
Q_{1}(t)=L(t)-\frac{\left(L(0)-u_{0}\right) \exp \left(A_{1}(t)\right)}{1+\left(L(0)-u_{0}\right) \int_{0}^{t} f(s) \exp \left(A_{1}(s)\right) d s}
$$

where $A_{1}(t)=\int_{0}^{t} 2(f(s) L(s)+f(s)+g(s)) d s$, and $L(t)$ is the maximal solution of the differential equation

$$
\frac{d L(t)}{d t}=q(t)+f(t) L^{2}(t)+(f(t)+g(t)) L(t), \quad \forall t \in I
$$

such that $L(0)>u_{0}$.

Lemma 3 Suppose that $\varphi(t)$ is a positive and increasing function on $I$ with $\varphi(0)=0$, $f_{i} \in C(I, I), i=1,2 ; u(t)$ is a nonnegative real-valued continuous function defined on $I$ with $u(0)=u_{0}>0$ and satisfies the inequality

$$
\frac{d u(t)}{d t} \leq f_{1}(t)+f_{2}(t) \varphi(u(t)), \quad \forall t \in I
$$

then $u(t)$ has the following estimation:

$$
u(t) \leq \Phi^{-1}\left(\Phi\left(u_{0}+\int_{0}^{t} f_{1}(s) d s\right)+\int_{0}^{t} f_{2}(s) d s\right), \quad \forall t \in\left[0, T_{1}\right]
$$

where

$$
\Phi(r):=\int_{1}^{r} \frac{d s}{\varphi(s)}, \quad r>0
$$

and $T_{1}$ is the largest number such that

$$
\Phi\left(u_{0}+\int_{0}^{T_{1}} f_{1}(s) d s\right)+\int_{0}^{T_{1}} f_{2}(s) d s \leq \int_{1}^{\infty} \frac{d s}{\varphi(s)}
$$

Remark $1 \Phi(t)=\ln (t)$ when $\varphi(t)=t$.

Proof Integrating both sides of (2.3) from 0 to $t$,

$$
\begin{aligned}
u(t) & \leq u_{0}+\int_{0}^{t} f_{1}(s) d s+\int_{0}^{t} f_{2}(s) \varphi(u(s)) d s \\
& \leq u_{0}+\int_{0}^{T} f_{1}(s) d s+\int_{0}^{t} f_{2}(s) \varphi(u(s)) d s, \quad \forall t \in[0, T]
\end{aligned}
$$

where $T \in\left[0, T_{1}\right]$ is a positive constant chosen arbitrarily, $T_{1}$ is defined by (2.6). Let

$$
R_{1}(t)=u_{0}+\int_{0}^{T} f_{1}(s) d s+\int_{0}^{t} f_{2}(s) \varphi(u(s)) d s, \quad \forall t \in[0, T]
$$


then $R_{1}(t)$ is a nonnegative and nondecreasing function on $I$ with $R_{1}(0)=u_{0}+\int_{0}^{T} f_{1}(s) d s$. Then (2.7) is equivalent to

$$
u(t) \leq R_{1}(t), \quad \forall t \in[0, T]
$$

Differentiating $R_{1}(t)$ with respect to $t$, from (2.8) and (2.9), we have

$$
\frac{d R_{1}(t)}{d t}=f_{2}(t) \varphi(u(t)) \leq f_{2}(t) \varphi\left(R_{1}(t)\right), \quad \forall t \in[0, T]
$$

Since $R_{1}(t)>0$, from (2.10) we have

$$
\frac{d R_{1}(t)}{\varphi\left(R_{1}(t)\right) d t} \leq f_{2}(t), \quad \forall t \in[0, T]
$$

By taking $t=s$ in (2.11) and integrating it from 0 to $t$, we get

$$
R_{1}(t) \leq \Phi^{-1}\left(\Phi\left(R_{1}(0)\right)+\int_{0}^{t} f_{2}(s) d s\right), \quad \forall t \in[0, T]
$$

where $\Phi$ is defined by (2.5). From (2.9) we have

$$
u(t) \leq \Phi^{-1}\left(\Phi\left(u_{0}+\int_{0}^{T} f_{1}(s) d s\right)+\int_{0}^{t} f_{2}(s) d s\right), \quad \forall t \in[0, T]
$$

Letting $t=T$, from (2.13) we get

$$
u(T) \leq \Phi^{-1}\left(\Phi\left(u_{0}+\int_{0}^{T} f_{1}(s) d s\right)+\int_{0}^{T} f_{2}(s) d s\right)
$$

Because $T \in\left[0, T_{1}\right]$ is chosen arbitrarily, this proves (2.4).

Lemma 4 Let $f_{i} \in C(I, I), i=1,2,3$; we assume that $u(t)$ is a nonnegative real-valued continuous function defined on $I$ with $u(0)=u_{0}>0$ and satisfies the inequality

$$
\frac{d u(t)}{d t} \leq f_{1}(t)+f_{2}(t) u(t)+f_{3}(t) u^{2}(t), \quad \forall t \in I
$$

then $u(t)$ has the following estimation:

$$
\begin{aligned}
u(t) \leq & \exp \left(\int_{0}^{t} f_{2}(s) d s\right)\left(\left(u_{0}+\int_{0}^{t} f_{1}(s) d s\right)^{-1}\right. \\
& \left.-\int_{0}^{t} f_{3}(s) \exp \left(\int_{0}^{s} f_{2}(\tau) d \tau\right) d s\right)^{-1},
\end{aligned}
$$

for all $t \in\left[0, T_{2}\right]$, where $T_{2}$ is the largest number such that

$$
\left(u_{0}+\int_{0}^{t} f_{1}(s) d s\right)^{-1}-\int_{0}^{t} f_{3}(s) \exp \left(\int_{0}^{s} f_{2}(\tau) d \tau\right) d s>0, \quad \forall t \in\left[0, T_{2}\right]
$$


Proof Integrating both sides of (2.14) from 0 to $t$, we get

$$
\begin{aligned}
u(t) \leq & u_{0}+\int_{0}^{t} f_{1}(s) d s+\int_{0}^{t} f_{2}(s) u(s) d s+\int_{0}^{t} f_{3}(s) u^{2}(s) d s \\
\leq & u_{0}+\int_{0}^{T} f_{1}(s) d s+\int_{0}^{t} f_{2}(s) u(s) d s \\
& +\int_{0}^{t} f_{3}(s) u^{2}(s) d s, \quad \forall t \in[0, T],
\end{aligned}
$$

where $T \in\left[0, T_{2}\right]$ is a positive constant chosen arbitrarily, $T_{2}$ is defined by (2.16). Let

$$
\begin{aligned}
R_{2}(t)= & u_{0}+\int_{0}^{T} f_{1}(s) d s+\int_{0}^{t} f_{2}(s) u(s) d s \\
& +\int_{0}^{t} f_{3}(s) u^{2}(s) d s, \quad \forall t \in[0, T],
\end{aligned}
$$

then $R_{2}(t)$ is a nonnegative and nondecreasing function on $I$ with $R_{2}(0)=u_{0}+\int_{0}^{T} f_{1}(s) d s$. Then (2.17) is equivalent to

$$
u(t) \leq R_{2}(t), \quad \forall t \in[0, T] .
$$

Differentiating $R_{2}(t)$ with respect to $t$, from (2.18) and (2.19), we have

$$
\frac{d R_{2}(t)}{d t}=f_{2}(t) u(t)+f_{3}(t) u^{2}(t) \leq f_{2}(t) R_{2}(t)+f_{3}(t) R_{2}^{2}(t), \quad \forall t \in[0, T] .
$$

Since $R_{2}(t)>0$, from $(2.20)$ we have

$$
R_{2}^{-2}(t) \frac{d R_{2}(t)}{d t} \leq f_{2}(t) R_{2}^{-1}(t)+f_{3}(t), \quad \forall t \in[0, T] .
$$

Let $S_{1}(t)=R_{2}^{-1}(t)$, then $S_{1}(0)=\left(u_{0}+\int_{0}^{T} f_{1}(s) d s\right)^{-1}$, from (2.21) we obtain

$$
\frac{d S_{1}(t)}{d t}+f_{2}(t) S_{1}(t) \geq-f_{3}(t), \quad \forall t \in[0, T]
$$

Consider the ordinary differential equation

$$
\left\{\begin{array}{l}
\frac{d S_{2}(t)}{d t}+f_{2}(t) S_{2}(t)=-f_{3}(t), \quad \forall t \in[0, T] \\
S_{2}(0)=\left(u_{0}+\int_{0}^{T} f_{1}(s) d s\right)^{-1}
\end{array}\right.
$$

The solution of equation (2.23) is

$$
\begin{aligned}
S_{2}(t)= & \exp \left(-\int_{0}^{t} f_{2}(s) d s\right)\left(\left(u_{0}+\int_{0}^{T} f_{1}(s) d s\right)^{-1}\right. \\
& \left.-\int_{0}^{t} f_{3}(s) \exp \left(\int_{0}^{s} f_{2}(\tau) d \tau\right) d s\right)
\end{aligned}
$$


for all $t \in[0, T]$. Letting $t=T$ in (2.24), from (2.19), (2.22), (2.23) and (2.24), we obtain

$$
\begin{aligned}
u(T) \leq & R_{2}(T)=\frac{1}{S_{1}(T)} \leq \frac{1}{S_{2}(T)} \\
\leq & \exp \left(\int_{0}^{T} f_{2}(s) d s\right)\left(\left(u_{0}+\int_{0}^{T} f_{1}(s) d s\right)^{-1}\right. \\
& \left.-\int_{0}^{T} f_{3}(s) \exp \left(\int_{0}^{s} f_{2}(\tau) d \tau\right) d s\right)^{-1} .
\end{aligned}
$$

Because $T \in\left[0, T_{2}\right]$ is chosen arbitrarily, this proves (2.15).

Lemma 5 Suppose that $\varphi(t), \varphi(t) / t$ are positive and increasing functions on $I, f_{i} \in C(I, I)$, $i=1,2,3,4 ; u(t)$ is a nonnegative real-valued continuous function defined on I with $u(0)=$ $u_{0}>0$ and satisfies the inequality

$$
\begin{aligned}
& \frac{d u(t)}{d t} \leq f_{1}(t)+f_{2}(t) u(t)+f_{3}(t) u(t) \varphi(u(t))+f_{4}(t) \varphi(u(t)), \\
& u(0)=u_{0}, \quad \forall t \in I,
\end{aligned}
$$

then $u(t)$ has the following estimation:

$$
\begin{aligned}
u(t) \leq & \exp \left(\Phi _ { 1 } ^ { - 1 } \left(\Phi_{1}\left(\ln \left(u_{0}+\int_{0}^{t} f_{1}(s) d s\right)+\int_{0}^{t} f_{2}(s) d s\right)+\int_{0}^{t} f_{3}(s) d s\right.\right. \\
& \left.\left.+\int_{0}^{t} \frac{f_{4}(s) d s}{\exp \left(\ln \left(u_{0}+\int_{0}^{t} f_{1}(\tau) d \tau\right)+\int_{0}^{t} f_{2}(\tau) d \tau\right)}\right)\right)
\end{aligned}
$$

for all $t \in\left[0, T_{3}\right]$, where

$$
\Phi_{1}(r):=\int_{1}^{r} \frac{d s}{\varphi(\exp (s))}, \quad r>0
$$

and $T_{3}$ is the largest number such that

$$
\begin{aligned}
& \Phi_{1}\left(\ln \left(u_{0}+\int_{0}^{T} f_{1}(s) d s\right)+\int_{0}^{T} f_{2}(s) d s\right)+\int_{0}^{T} f_{3}(s) d s \\
& \quad+\int_{0}^{T} \frac{f_{4}(s) d s}{\exp \left(\ln \left(u_{0}+\int_{0}^{T} f_{1}(\tau) d \tau\right)+\int_{0}^{T} f_{2}(\tau) d \tau\right)} \leq \int_{1}^{\infty} \frac{d s}{\varphi(\exp (s))} .
\end{aligned}
$$

Proof Integrating both sides of (2.26) from 0 to $t$, we get

$$
\begin{aligned}
u(t) \leq & u_{0}+\int_{0}^{t} f_{1}(s) d s+\int_{0}^{t} f_{2}(s) u(s) d s+\int_{0}^{t} f_{3}(s) u(s) \varphi(u(s)) d s+\int_{0}^{t} f_{4}(s) \varphi(u(s)) d s \\
\leq & u_{0}+\int_{0}^{T} f_{1}(s) d s+\int_{0}^{t} f_{2}(s) u(s) d s \\
& +\int_{0}^{t} f_{3}(s) u(s) \varphi(u(s)) d s+\int_{0}^{t} f_{4}(s) \varphi(u(s)) d s
\end{aligned}
$$


for all $t \in[0, T]$, where $T \in\left[0, T_{3}\right]$ is a positive constant chosen arbitrarily, $T_{3}$ is defined by (2.29). Let $R_{3}(t)$ denote the function on the right-hand side of (2.30), which is a positive and nondecreasing function on $[0, T]$ with

$$
R_{3}(0)=u_{0}+\int_{0}^{T} f_{1}(s) d s
$$

Then (2.26) is equivalent to

$$
u(t) \leq R_{3}(t), \quad \forall t \in[0, T]
$$

Differentiating $R_{3}(t)$ with respect to $t$ and using (2.32), we have

$$
\frac{d R_{3}(t)}{d t} \leq f_{2}(t) R_{3}(t)+f_{3}(t) R_{3}(t) \varphi\left(R_{3}(t)\right)+f_{4}(t) \varphi\left(R_{3}(t)\right), \quad \forall t \in[0, T] .
$$

From (2.33) we get

$$
R_{3}^{-1}(t) \frac{d R_{3}(t)}{d t} \leq f_{2}(t)+f_{3}(t) \varphi\left(R_{3}(t)\right)+f_{4}(t) \varphi\left(R_{3}(t)\right) R_{3}^{-1}(t), \quad \forall t \in[0, T] .
$$

Integrating both sides of (2.34) from 0 to $t$ and using (2.31), we get

$$
\begin{aligned}
R_{3}(t) \leq & \exp \left(\ln R_{3}(0)+\int_{0}^{t} f_{2}(s) d s+\int_{0}^{t} f_{3}(s) \varphi\left(R_{3}(s)\right) d s+\int_{0}^{t} f_{4}(s) \varphi\left(R_{3}(s)\right) R_{3}^{-1}(s) d s\right) \\
\leq & \exp \left(\ln \left(u_{0}+\int_{0}^{T} f_{1}(s) d s\right)+\int_{0}^{T} f_{2}(s) d s+\int_{0}^{t} f_{3}(s) \varphi\left(R_{3}(s)\right) d s\right. \\
& \left.+\int_{0}^{t} f_{4}(s) \varphi\left(R_{3}(s)\right) R_{3}^{-1}(s) d s\right), \quad \forall t \in[0, T]
\end{aligned}
$$

here we use the monotonicity of $\varphi(t)$ and $\varphi(t) / t$. Let

$$
\begin{aligned}
R_{4}(t)= & \ln \left(u_{0}+\int_{0}^{T} f_{1}(s) d s\right)+\int_{0}^{T} f_{2}(s) d s+\int_{0}^{t} f_{3}(s) \varphi\left(R_{3}(s)\right) d s \\
& +\int_{0}^{t} f_{4}(s) \varphi\left(R_{3}(s)\right) R_{3}^{-1}(s) d s
\end{aligned}
$$

for all $t \in[0, T]$, then $R_{4}(t)$ is a positive and nondecreasing function on $[0, T]$ with

$$
R_{4}(0)=\ln \left(u_{0}+\int_{0}^{T} f_{1}(s) d s\right)+\int_{0}^{T} f_{2}(s) d s .
$$

(2.36) is equivalent to

$$
R_{3}(t) \leq \exp \left(R_{4}(t)\right), \quad \forall t \in[0, T] .
$$

Differentiating $R_{4}(t)$ with respect to $t$ and using (2.38), we have

$$
\begin{aligned}
\frac{d R_{4}(t)}{d t} & =f_{3}(t) \varphi\left(R_{3}(t)\right)+f_{4}(t) \varphi\left(R_{3}(t)\right) R_{3}^{-1}(t) \\
& \leq f_{3}(t) \varphi\left(\exp \left(R_{4}(t)\right)\right)+f_{4}(t) \varphi\left(\exp \left(R_{4}(t)\right)\right)\left(\exp \left(R_{4}(t)\right)\right)^{-1}, \quad \forall t \in[0, T]
\end{aligned}
$$


From (2.39) we get

$$
\varphi^{-1}\left(\exp \left(R_{4}(t)\right)\right) \frac{d R_{4}(t)}{d t} \leq f_{3}(t)+f_{4}(t)\left(\exp \left(R_{4}(t)\right)\right)^{-1}, \quad \forall t \in[0, T]
$$

Integrating both sides of (2.40) from 0 to $t$,

$$
\begin{aligned}
\Phi_{1}\left(R_{4}(t)\right) \leq & \Phi_{1}\left(R_{4}(0)\right)+\int_{0}^{t} f_{3}(s) d s+\int_{0}^{t} f_{4}(s)\left(\exp \left(R_{4}(0)\right)\right)^{-1} d s \\
\leq & \Phi_{1}\left(\ln \left(u_{0}+\int_{0}^{T} f_{1}(s) d s\right)+\int_{0}^{T} f_{2}(s) d s\right)+\int_{0}^{t} f_{3}(s) d s \\
& +\int_{0}^{t} \frac{f_{4}(s) d s}{\exp \left(\ln \left(u_{0}+\int_{0}^{T} f_{1}(\tau) d \tau\right)+\int_{0}^{T} f_{2}(\tau) d \tau\right)}
\end{aligned}
$$

for all $t \in[0, T]$, where $\Phi_{1}$ is defined by (2.28). From (2.32), (2.38) and (2.41), we have

$$
\begin{aligned}
u(t) \leq & R_{3}(t) \leq \exp \left(R_{4}(t)\right) \\
\leq & \exp \left(\Phi _ { 1 } ^ { - 1 } \left(\Phi_{1}\left(\ln \left(u_{0}+\int_{0}^{T} f_{1}(s) d s\right)+\int_{0}^{T} f_{2}(s) d s\right)+\int_{0}^{t} f_{3}(s) d s\right.\right. \\
& \left.\left.+\int_{0}^{t} \frac{f_{4}(s) d s}{\exp \left(\ln \left(u_{0}+\int_{0}^{T} f_{1}(\tau) d \tau\right)+\int_{0}^{T} f_{2}(\tau) d \tau\right)}\right)\right)
\end{aligned}
$$

for all $t \in[0, T]$. Letting $t=T$, from (2.42) we get

$$
\begin{aligned}
u(T) \leq & \exp \left(\Phi _ { 1 } ^ { - 1 } \left(\Phi_{1}\left(\ln \left(u_{0}+\int_{0}^{T} f_{1}(s) d s\right)+\int_{0}^{T} f_{2}(s) d s\right)+\int_{0}^{T} f_{3}(s) d s\right.\right. \\
& \left.\left.+\int_{0}^{T} \frac{f_{4}(s) d s}{\exp \left(\ln \left(u_{0}+\int_{0}^{T} f_{1}(\tau) d \tau\right)+\int_{0}^{T} f_{2}(\tau) d \tau\right)}\right)\right) .
\end{aligned}
$$

Because $T \in\left[0, T_{3}\right]$ is chosen arbitrarily, this gives the estimation (2.27) of the unknown function in the inequality (2.26).

Theorem 1 Suppose that $\alpha \in C^{1}(I, I)$ is an increasing function with $\alpha(t) \leq t, \alpha(0)=0$, $\forall t \in I ; u(t), f(t), q(t)$ and $g(t)$ are nonnegative real-valued continuous functions defined on $I=[0, \infty)$ and satisfy the inequality (1.1). Then

$$
u(t) \leq \exp \left(\ln \left(u_{0}+\int_{0}^{\alpha(t)} q(s) d s\right)+\int_{0}^{\alpha(t)}\left(f(s)+f(s) L_{1}\left(\alpha^{-1}(s)\right)\right) d s\right)
$$

for all $t \in\left[0, T_{4}\right]$, where

$$
\begin{aligned}
L_{1}(t)= & \exp \left(\int_{0}^{\alpha(t)}(f(s)+g(s)) d s\right)\left(\left(u_{0}+\int_{0}^{\alpha(t)} q(s) d s\right)^{-1}\right. \\
& \left.-\int_{0}^{\alpha(t)} f(s) \exp \left(\int_{0}^{s}(f(\tau)+g(\tau)) d \tau\right) d s\right)^{-1},
\end{aligned}
$$


$T_{4}$ is the largest number such that

$$
\left(u_{0}+\int_{0}^{\alpha(t)} q(s) d s\right)^{-1}-\int_{0}^{\alpha(t)} f(s) \exp \left(\int_{0}^{s}(f(\tau)+g(\tau)) d \tau\right) d s>0 .
$$

Remark 2 Theorem 1 gives the explicit estimation (2.43) for the inequality (1.1) which is just the inequality (2.1) when $\alpha(t)=t$. Lemma 1 gives the implicit estimation (2.2) for the inequality (2.1).

Proof Let $z_{1}(t)$ denote the function on the right-hand side of (1.1), which is a positive and nondecreasing function on $I$ with $z_{1}(0)=u_{0}$. Then (1.1) is equivalent to

$$
u(t) \leq z_{1}(t), \quad u(\alpha(t)) \leq z_{1}(\alpha(t)) \leq z_{1}(t), \quad \forall t \in I .
$$

Differentiating $z_{1}(t)$ with respect to $t$ and using (2.45), we have

$$
\begin{aligned}
\frac{d z_{1}(t)}{d t}= & \alpha^{\prime}(t) f(\alpha(t)) u(\alpha(t))+\alpha^{\prime}(t) q(\alpha(t)) \\
& +\alpha^{\prime}(t) f(\alpha(t)) u(\alpha(t))\left[u(\alpha(t))+\int_{0}^{\alpha(t)} g(\lambda) u(\lambda) d \lambda\right] \\
\leq & \alpha^{\prime}(t) q(\alpha(t))+\left[\alpha^{\prime}(t) f(\alpha(t))+\alpha^{\prime}(t) f(\alpha(t)) Y_{1}(t)\right] z_{1}(t), \quad \forall t \in I,
\end{aligned}
$$

where

$$
Y_{1}(t):=z_{1}(t)+\int_{0}^{\alpha(t)} g(\lambda) z_{1}(\lambda) d \lambda, \quad \forall t \in I .
$$

Then $Y_{1}(t)$ is a positive and nondecreasing function on $I$ with $Y_{1}(0)=z_{1}(0)=u_{0}$ and

$$
z_{1}(t) \leq Y_{1}(t)
$$

Differentiating $Y_{1}(t)$ with respect to $t$ and using (2.46), (2.47) and (2.48), we get

$$
\begin{aligned}
\frac{d Y_{1}(t)}{d t} & \leq \alpha^{\prime}(t) q(\alpha(t))+\left[\alpha^{\prime}(t) f(\alpha(t))+\alpha^{\prime}(t) f(\alpha(t)) Y_{1}(t)\right] z_{1}(t)+\alpha^{\prime}(t) g(\alpha(t)) z_{1}(t) \\
& \leq \alpha^{\prime}(t) q(\alpha(t))+\left[\alpha^{\prime}(t) f(\alpha(t))+\alpha^{\prime}(t) g(\alpha(t))\right] Y_{1}(t)+\alpha^{\prime}(t) f(\alpha(t)) Y_{1}^{2}(t)
\end{aligned}
$$

for all $t \in I$. Applying Lemma 4 to (2.49), we obtain

$$
Y_{1}(t) \leq L_{1}(t), \quad \forall t \in\left[0, T_{4}\right]
$$

From (2.46) and (2.50), we get

$$
\frac{d z_{1}(t)}{d t} \leq \alpha^{\prime}(t) q(\alpha(t))+\left[\alpha^{\prime}(t) f(\alpha(t))+\alpha^{\prime}(t) f(\alpha(t)) L_{1}(t)\right] z_{1}(t), \quad \forall t \in\left[0, T_{4}\right] .
$$

Applying Lemma 3 to (2.51) and using Remark 1, we obtain

$$
z_{1}(t) \leq \exp \left(\ln \left(u_{0}+\int_{0}^{\alpha(t)} q(s) d s\right)+\int_{0}^{\alpha(t)}\left(f(s)+f(s) L_{1}\left(\alpha^{-1}(s)\right)\right) d s\right), \quad \forall t \in\left[0, T_{4}\right] .
$$


From (2.45), the estimation (2.43) of the unknown function in the inequality (1.1) is obtained.

Theorem 2 Suppose $\varphi \in C(I, I)$ and $\alpha \in C^{1}(I, I)$ are increasing functions with $\alpha(t) \leq t$, $\alpha(0)=0, \forall t \in I$. We assume that $u(t), f(t), q(t)$ and $g(t)$ are nonnegative real-valued continuous functions defined on I and satisfy the inequality (1.2). Then

$$
\begin{aligned}
u(t) \leq & \Phi^{-1}\left(\Phi\left(u_{0}+\int_{0}^{\alpha(t)} q(s) d s\right)\right. \\
& \left.+\int_{0}^{\alpha(t)}\left(f(s)+f(s) L_{2}\left(\alpha^{-1}(s)\right)\right) d s\right), \quad \forall t \in\left[0, T_{4}\right]
\end{aligned}
$$

where $\Phi$ is defined by (2.5),

$$
\begin{aligned}
L_{2}(t)= & \exp \left(\Phi _ { 1 } ^ { - 1 } \left(\Phi_{1}\left(\ln \left(u_{0}+\int_{0}^{\alpha(t)} q(s) d s\right)+\int_{0}^{\alpha(t)} g(s) d s\right)+\int_{0}^{\alpha(t)} f(s) d s\right.\right. \\
& \left.\left.+\int_{0}^{\alpha(t)} \frac{f(s) d s}{\exp \left(\ln \left(u_{0}+\int_{0}^{\alpha(t)} q(s) d s\right)+\int_{0}^{\alpha(t)} g(s) d s\right)}\right)\right), \quad \forall t \in\left[0, T_{4}\right],
\end{aligned}
$$

$\Phi_{1}$ is defined by (2.28), $T_{4}$ is the largest number such that

$$
\begin{aligned}
& \Phi\left(u_{0}+\int_{0}^{\alpha(t)} q(s) d s\right)+\int_{0}^{\alpha(t)}\left(f(s)+f(s) L_{2}\left(\alpha^{-1}(s)\right)\right) d s \leq \int_{1}^{\infty} \frac{d s}{\varphi(s)} \\
& \Phi_{1}\left(\ln \left(u_{0}+\int_{0}^{\alpha\left(T_{4}\right)} q(s) d s\right)+\int_{0}^{\alpha\left(T_{4}\right)} g(s) d s\right)+\int_{0}^{\alpha\left(T_{4}\right)} f(s) d s \\
& \quad+\int_{0}^{\alpha\left(T_{4}\right)} \frac{f(s) d s}{\exp \left(\ln \left(u_{0}+\int_{0}^{\alpha\left(T_{4}\right)} q(s) d s\right)+\int_{0}^{\alpha\left(T_{4}\right)} g(s) d s\right)} \leq \int_{1}^{\infty} \frac{d s}{\varphi(\exp (s))} .
\end{aligned}
$$

Proof Let $z_{2}(t)$ denote the function on the right-hand side of (1.2), which is a positive and nondecreasing function on $I$ with $z_{2}(0)=u_{0}$. Then (1.2) is equivalent to

$$
u(t) \leq z_{2}(t), \quad u(\alpha(t)) \leq z_{2}(\alpha(t)) \leq z_{2}(t), \quad \forall t \in I
$$

Differentiating $z_{2}(t)$ with respect to $t$ and using (2.55), we have

$$
\begin{aligned}
\frac{d z_{2}(t)}{d t}= & \alpha^{\prime}(t) f(\alpha(t)) \varphi(u(\alpha(t)))+\alpha^{\prime}(t) q(\alpha(t)) \\
& +\alpha^{\prime}(t) f(\alpha(t)) \varphi(u(\alpha(t)))\left[u(\alpha(t))+\int_{0}^{\alpha(t)} g(\lambda) u(\lambda) d \lambda\right] \\
\leq & \alpha^{\prime}(t) q(\alpha(t))+\left[\alpha^{\prime}(t) f(\alpha(t))+\alpha^{\prime}(t) f(\alpha(t)) Y_{2}(t)\right] \varphi\left(z_{2}(t)\right), \quad \forall t \in I,
\end{aligned}
$$

where

$$
Y_{2}(t):=z_{2}(t)+\int_{0}^{\alpha(t)} g(\lambda) z_{2}(\lambda) d \lambda, \quad \forall t \in I
$$


Then $Y_{2}(t)$ is a positive and nondecreasing function on $I$ with $Y_{2}(0)=z_{2}(0)=u_{0}$ and

$$
z_{2}(t) \leq Y_{2}(t)
$$

Differentiating $Y_{2}(t)$ with respect to $t$ and using (2.56), (2.57) and (2.58), we get

$$
\begin{aligned}
\frac{d Y_{2}(t)}{d t} \leq & \alpha^{\prime}(t) q(\alpha(t))+\left[\alpha^{\prime}(t) f(\alpha(t))+\alpha^{\prime}(t) f(\alpha(t)) Y_{2}(t)\right] \varphi\left(z_{2}(t)\right)+\alpha^{\prime}(t) g(\alpha(t)) z_{2}(t) \\
\leq & \alpha^{\prime}(t) q(\alpha(t))+\alpha^{\prime}(t) g(\alpha(t)) Y_{2}(t)+\alpha^{\prime}(t) f(\alpha(t)) Y_{2}(t) \varphi\left(Y_{2}(t)\right) \\
& +\alpha^{\prime}(t) f(\alpha(t)) \varphi\left(Y_{2}(t)\right)
\end{aligned}
$$

for all $t \in I$. Applying Lemma 5 to (2.59), we obtain

$$
\begin{aligned}
Y_{2}(t) \leq & \exp \left(\Phi _ { 1 } ^ { - 1 } \left(\Phi_{1}\left(\ln \left(u_{0}+\int_{0}^{\alpha(t)} q(s) d s\right)+\int_{0}^{\alpha(t)} g(s) d s\right)+\int_{0}^{\alpha(t)} f(s) d s\right.\right. \\
& \left.\left.+\int_{0}^{\alpha(t)} \frac{f(s) d s}{\exp \left(\ln \left(u_{0}+\int_{0}^{\alpha(t)} q(s) d s\right)+\int_{0}^{\alpha(t)} g(s) d s\right)}\right)\right) \\
= & L_{2}(t), \quad \forall t \in\left[0, T_{4}\right],
\end{aligned}
$$

where $T_{4}$ and $L_{2}$ are defined by (2.53) and (2.54) respectively. From (2.56) and (2.60), we get

$$
\begin{aligned}
\frac{d z_{2}(t)}{d t} \leq & \alpha^{\prime}(t) q(\alpha(t))+\left[\alpha^{\prime}(t) f(\alpha(t))\right. \\
& \left.+\alpha^{\prime}(t) f(\alpha(t)) L_{2}(t)\right] \varphi\left(z_{2}(t)\right), \quad \forall t \in\left[0, T_{4}\right]
\end{aligned}
$$

Applying Lemma 3 to (2.61), we obtain

$$
z_{2}(t) \leq \Phi^{-1}\left(\Phi\left(u_{0}+\int_{0}^{\alpha(t)} q(s) d s\right)+\int_{0}^{\alpha(t)}\left(f(s)+f(s) L_{2}\left(\alpha^{-1}(s)\right)\right) d s\right), \quad \forall t \in\left[0, T_{4}\right]
$$

where $\Phi$ is defined by (2.5). From (2.55), the estimation (2.52) of the unknown function in the inequality (1.2) is obtained.

Theorem 3 Suppose $\alpha \in C^{1}(I, I)$ are increasing functions with $\alpha(t) \leq t, \alpha(0)=0, \forall t \in I$. We assume that $u(t), f(t)$ and $g(t)$ are nonnegative real-valued continuous functions defined on I and satisfy the inequality (1.3). Then

$$
u(t) \leq u_{0} \exp \left(\int_{0}^{t} f(s) B_{2}(s)\right) d s, \quad \forall t \in I
$$

where

$$
B_{2}(t)=\frac{u_{0}^{p} \exp \left(p \int_{0}^{\alpha(t)} g(s) d s\right)}{1-p u_{0}^{p} \int_{0}^{\alpha(t)} f(s) \exp \left(p \int_{0}^{s} g(\tau) d \tau\right) d s}
$$

such that $p u_{0}^{p} \int_{0}^{\alpha(t)} f(s) \exp \left(p \int_{0}^{s} g(\tau) d \tau\right) d s \leq 1$ for all $t \in I$. 
Remark 3 If $\alpha(t)=t$, then Theorem 3 reduces Lemma 1 .

Proof Let $z_{3}(t)$ denote the function on the right-hand side of (1.3), which is a positive and nondecreasing function on $I$ with $z_{3}(0)=u_{0}$. Then (1.3) is equivalent to

$$
u(t) \leq z_{3}(t), \quad u(\alpha(t)) \leq z_{3}(\alpha(t)) \leq z_{3}(t), \quad \forall t \in I .
$$

Differentiating $z_{3}(t)$ with respect to $t$ and using (2.64), we have

$$
\begin{aligned}
\frac{d z_{3}(t)}{d t} & =\alpha^{\prime}(t) f(\alpha(t)) u(\alpha(t))\left[u(\alpha(t))+\int_{0}^{\alpha(t)} g(\lambda) u(\lambda) d \lambda\right]^{p} \\
& \leq \alpha^{\prime}(t) f(\alpha(t)) z_{3}(t)\left[z_{3}(t)+\int_{0}^{\alpha(t)} g(\lambda) z_{3}(\lambda) d \lambda\right]^{p} \\
& =\alpha^{\prime}(t) f(\alpha(t)) z_{3}(t) Y_{3}^{p}(t), \quad \forall t \in I
\end{aligned}
$$

where

$$
Y_{3}(t):=z_{3}(t)+\int_{0}^{\alpha(t)} g(\lambda) z_{3}(\lambda) d \lambda, \quad \forall t \in I
$$

Then $Y_{3}(t)$ is a positive and nondecreasing function on $I$ with $Y_{3}(0)=z_{3}(0)=u_{0}$ and

$$
z_{3}(t) \leq Y_{3}(t)
$$

Differentiating $Y_{3}(t)$ with respect to $t$ and using (2.65), (2.66) and (2.67), we get

$$
\begin{aligned}
\frac{d Y_{3}(t)}{d t} & \leq \alpha^{\prime}(t) f(\alpha(t)) z_{3}(t) Y_{3}^{p}(t)+\alpha^{\prime}(t) g(\alpha(t)) z_{3}(t) \\
& \leq \alpha^{\prime}(t) f(\alpha(t)) Y_{3}^{1+p}(t)+\alpha^{\prime}(t) g(\alpha(t)) Y_{3}(t), \quad \forall t \in I .
\end{aligned}
$$

From (2.68) we have

$$
Y_{3}^{-(1+p)}(t) \frac{d Y_{3}(t)}{d t}-\alpha^{\prime}(t) g(\alpha(t)) Y_{3}^{-p}(t) \leq \alpha^{\prime}(t) f(\alpha(t)), \quad \forall t \in I
$$

Let $S_{3}(t)=Y_{3}^{-p}(t)$, then $S_{3}(0)=u_{0}^{-p}$. From (2.69) we obtain

$$
\frac{d S_{3}(t)}{d t}+p \alpha^{\prime}(t) g(\alpha(t)) S_{3}(t) \leq-p \alpha^{\prime}(t) f(\alpha(t)), \quad \forall t \in I
$$

Consider the ordinary differential equation

$$
\left\{\begin{array}{l}
\frac{d S_{4}(t)}{d t}+p \alpha^{\prime}(t) g(\alpha(t)) S_{4}(t)=-p \alpha^{\prime}(t) f(\alpha(t)), \quad \forall t \in I, \\
S_{4}(0)=u_{0}^{-p}
\end{array}\right.
$$

The solution of equation (2.71) is

$$
S_{4}(t)=\exp \left(-\int_{0}^{\alpha(t)} p g(s) d s\right)\left(u_{0}^{-p}-\int_{0}^{\alpha(t)} p f(s) \exp \left(\int_{0}^{s} p g(\tau) d \tau\right) d s\right)
$$


for all $t \in I$. By (2.70), (2.71) and (2.72), we obtain

$$
Y_{3}^{p}(t)=S_{3}^{-1}(t) \leq S_{4}^{-1}(t)=B_{2}(t), \quad \forall t \in I,
$$

where $B_{2}(t)$ is as defined in (2.63). From (2.65) and (2.73), we have

$$
\frac{d z_{3}(t)}{d t} \leq \alpha^{\prime}(t) f(\alpha(t)) z_{3}(t) B_{2}(t), \quad \forall t \in I
$$

By taking $t=s$ in the above inequality and integrating it from 0 to $t$, from (2.64) we get

$$
u(t) \leq z_{3}(t) \leq u_{0} \exp \left(\int_{0}^{\alpha(t)} f(s) B_{2}(s)\right) d s, \quad \forall t \in I
$$

The estimation (2.62) of the unknown function in the inequality (1.3) is obtained.

Theorem 4 Suppose $\varphi_{1}, \varphi_{2}, \alpha \in C^{1}(I, I)$ are increasing functions with $\varphi_{i}(t)>0, \alpha(t) \leq t$, $\forall t>0, i=1,2, \alpha(0)=0$. We assume that $u(t), f(t)$ and $g(t)$ are nonnegative real-valued continuous functions defined on $I=[0, \infty)$ and satisfy the inequality (1.4). Then

$$
u(t) \leq \Phi_{2}^{-1}\left[\Phi_{3}^{-1}\left(\Phi_{3}\left(\Phi_{2}\left(u_{0}\right)+\int_{0}^{\alpha(t)} g(s) d s\right)+\int_{0}^{\alpha(t)} f(s) d s\right)\right], \quad \forall t<T_{5},
$$

where

$$
\begin{aligned}
& \Phi_{2}(r):=\int_{1}^{r} \frac{d t}{\varphi_{2}(t)}, \quad r>0, \\
& \Phi_{3}(r):=\int_{1}^{r} \frac{\varphi_{2}\left(\Phi_{2}^{-1}(s)\right) d s}{\varphi_{1}\left(\Phi_{2}^{-1}(s)\right)\left(\Phi_{2}^{-1}(s)\right)^{p}}, \quad r>0,
\end{aligned}
$$

and $T_{5}$ is the largest number such that

$$
\begin{aligned}
& \Phi_{3}\left(\Phi_{2}\left(u_{0}\right)+\int_{0}^{\alpha(t)} g(s) d s\right)+\int_{0}^{\alpha(t)} f(s) d s \leq \int_{1}^{\infty} \frac{\varphi_{2}\left(\Phi_{2}^{-1}(s)\right) d s}{\varphi_{1}\left(\Phi_{2}^{-1}(s)\right)\left(\Phi_{2}^{-1}(s)\right)^{p}}, \\
& \Phi_{3}^{-1}\left(\Phi_{3}\left(\Phi_{2}\left(u_{0}\right)+\int_{0}^{\alpha(t)} g(s) d s\right)+\int_{0}^{\alpha(t)} f(s) d s\right) \leq \int_{1}^{\infty} \frac{d t}{\varphi_{2}(t)} .
\end{aligned}
$$

Proof Let $z_{4}(t)$ denote the function on the right-hand side of (1.4), which is a positive and nondecreasing function on $I$ with $z_{4}(0)=u_{0}$. Then (1.4) is equivalent to

$$
u(t) \leq z_{4}(t), \quad u(\alpha(t)) \leq z_{4}(\alpha(t)) \leq z_{4}(t), \quad \forall t \in I .
$$

Differentiating $z_{4}(t)$ with respect to $t$ and using (2.77), we have

$$
\begin{aligned}
\frac{d z_{4}(t)}{d t} & =\alpha^{\prime}(t) f(\alpha(t)) \varphi_{1}(u(\alpha(t)))\left[u(\alpha(t))+\int_{0}^{\alpha(t)} g(\lambda) \varphi_{2}(u(\lambda)) d \lambda\right]^{p} \\
& \leq \alpha^{\prime}(t) f(\alpha(t)) \varphi_{1}\left(z_{4}(t)\right)\left[z_{4}(t)+\int_{0}^{\alpha(t)} g(\lambda) \varphi_{2}\left(z_{4}(\lambda)\right) d \lambda\right]^{p} \\
& =\alpha^{\prime}(t) f(\alpha(t)) \varphi_{1}\left(z_{4}(t)\right) Y_{4}^{p}(t), \quad \forall t \in I,
\end{aligned}
$$


where

$$
Y_{4}(t):=z_{4}(t)+\int_{0}^{\alpha(t)} g(\lambda) \varphi_{2}\left(z_{4}(\lambda)\right) d \lambda, \quad \forall t \in I
$$

Then $Y_{4}(t)$ is a positive and nondecreasing function on $I$ with $Y_{4}(0)=z_{4}(0)=u_{0}$ and

$$
z_{4}(t) \leq Y_{4}(t)
$$

Differentiating $Y_{4}(t)$ with respect to $t$ and using (2.78), (2.79) and (2.80), we get

$$
\begin{aligned}
\frac{d Y_{4}(t)}{d t} & \leq \alpha^{\prime}(t) f(\alpha(t)) \varphi_{1}\left(z_{4}(t)\right) Y_{4}^{p}(t)+\alpha^{\prime}(t) g(\alpha(t)) \varphi_{2}\left(z_{4}(t)\right) \\
& \leq \alpha^{\prime}(t) f(\alpha(t)) \varphi_{1}\left(Y_{4}(t)\right) Y_{4}^{p}(t)+\alpha^{\prime}(t) g(\alpha(t)) \varphi_{2}\left(Y_{4}(t)\right), \quad \forall t \in I .
\end{aligned}
$$

Since $\varphi_{2}\left(Y_{4}(t)\right)>0, \forall t>0$, from $(2.81)$ we have

$$
\frac{d Y_{4}(t)}{\varphi_{2}\left(Y_{4}(t)\right)} \leq \alpha^{\prime}(t) f(\alpha(t)) \frac{\varphi_{1}\left(Y_{4}(t)\right) Y_{4}^{p}(t)}{\varphi_{2}\left(Y_{4}(t)\right)} d t+\alpha^{\prime}(t) g(\alpha(t)) d t, \quad \forall t \in I .
$$

By taking $t=s$ in the above inequality and integrating it from 0 to $t$, we get

$$
\begin{aligned}
\Phi_{2}\left(Y_{4}(t)\right) \leq & \Phi_{2}\left(Y_{4}(0)\right)+\int_{0}^{t} \alpha^{\prime}(s) f(\alpha(s)) \frac{\varphi_{1}\left(Y_{4}(s)\right) Y_{4}^{p}(s)}{\varphi_{2}\left(Y_{4}(s)\right)} d s \\
& +\int_{0}^{t} \alpha^{\prime}(s) g(\alpha(s)) d s
\end{aligned}
$$

for all $t \in I$, where $\Phi_{2}$ is defined by (2.75). From (2.82) we have

$$
\begin{aligned}
\Phi_{2}\left(Y_{4}(t)\right) \leq & \Phi_{2}\left(Y_{4}(0)\right)+\int_{0}^{T} \alpha^{\prime}(s) g(\alpha(s)) d s \\
& +\int_{0}^{t} \alpha^{\prime}(s) f(\alpha(s)) \frac{\varphi_{1}\left(Y_{4}(s)\right) Y_{4}^{p}(s)}{\varphi_{2}\left(Y_{4}(s)\right)} d s
\end{aligned}
$$

for all $t<T$, where $0<T<T_{5}$ is chosen arbitrarily. Let $Y_{5}(t)$ denote the function on the right-hand side of (2.83), which is a positive and nondecreasing function on $I$ with $Y_{5}(0)=$ $\Phi_{2}\left(u_{0}\right)+\int_{0}^{T} \alpha^{\prime}(s) g(\alpha(s)) d s$ and

$$
Y_{4}(t) \leq \Phi_{2}^{-1}\left(Y_{5}(t)\right), \quad \forall t<T
$$

Differentiating $Y_{5}(t)$ with respect to $t$ and using the hypothesis on $\varphi_{2} / \varphi_{1}$, from (2.84) we have

$$
\begin{aligned}
\frac{d Y_{5}(t)}{d t} & \leq \alpha^{\prime}(t) f(\alpha(t)) \frac{\varphi_{1}\left(Y_{4}(t)\right) Y_{4}^{p}(t)}{\varphi_{2}\left(Y_{4}(t)\right)} \\
& \leq \alpha^{\prime}(t) f(\alpha(t)) \frac{\varphi_{1}\left(\Phi_{2}^{-1}\left(Y_{5}(t)\right)\right)\left(\Phi_{2}^{-1}\left(Y_{5}(t)\right)\right)^{p}}{\varphi_{2}\left(\Phi_{2}^{-1}\left(Y_{5}(t)\right)\right)}, \quad \forall t<T .
\end{aligned}
$$


By the definition of $\Phi_{3}$ in (2.76), from (2.85) we obtain

$$
\begin{aligned}
\Phi_{3}\left(Y_{5}(t)\right) & \leq \Phi_{3}\left(Y_{5}(0)\right)+\int_{0}^{t} \alpha^{\prime}(s) f(\alpha(s)) d s \\
& \leq \Phi_{3}\left(\Phi_{2}\left(u_{0}\right)+\int_{0}^{\alpha(T)} g(s) d s\right)+\int_{0}^{\alpha(t)} f(s) d s, \quad \forall t<T .
\end{aligned}
$$

Let $t=T$, from (2.86) we have

$$
\begin{aligned}
\Phi_{3}\left(Y_{5}(T)\right) \leq & \Phi_{3}\left(\Phi_{2}\left(u_{0}\right)+\int_{0}^{\alpha(T)} g(s) d s\right) \\
& +\int_{0}^{\alpha(T)} f(s) d s, \quad \forall t<T .
\end{aligned}
$$

Since $0<T<T_{5}$ is chosen arbitrarily, from (2.77), (2.80), (2.84) and (2.87), we have

$$
u(t) \leq \Phi_{2}^{-1}\left[\Phi_{3}^{-1}\left(\Phi_{3}\left(\Phi_{2}\left(u_{0}\right)+\int_{0}^{\alpha(t)} g(s) d s\right)+\int_{0}^{\alpha(t)} f(s) d s\right)\right], \quad \forall t<T_{5}
$$

This proves (2.74).

\section{Application}

In this section we apply our Theorem 4 to the following differential-integral equation:

$$
\left\{\begin{array}{l}
\frac{d x(t)}{d t}=H\left(t, x(\alpha(t)), \int_{0}^{t} K(s, x(\alpha(s))) d s\right), \quad \forall t \in I \\
x(0)=x_{0}
\end{array}\right.
$$

where $K \in C(\mathbf{R} \times \mathbf{R}, \mathbf{R}), H \in C\left(\mathbf{R}^{3}, \mathbf{R}\right),\left|x_{0}\right|>0$ is a constant, satisfy the following conditions:

$$
\begin{aligned}
& |K(t, x(t))| \leq g(t) \psi_{2}(|x(t)|), \\
& \left|H\left(t, x(\alpha(t)), \int_{0}^{t} K(s, x(\alpha(s))) d s\right)\right| \\
& \quad \leq f(t) \psi_{1}(|\alpha(t)|)\left(|x(t)|+\int_{0}^{t}|K(s, x(\alpha(s)))| d s\right)^{p},
\end{aligned}
$$

where $f, g$ are nonnegative real-valued continuous functions defined on $I$.

Corollary 1 Consider the nonlinear system (3.88) and suppose that $K, H$ satisfy the conditions (3.89) and (3.90), and $\psi_{1}, \psi_{2}, \psi_{2} / \psi_{1}, \alpha \in C^{1}(I, I)$ are increasing functions with $\alpha(t) \leq t, \psi_{i}(t)>0, \forall t>0, i=1,2, \alpha(0)=0$. Then all the solutions of equation (3.88) exist on I and satisfy the following estimation:

$$
\begin{aligned}
|x(t)| \leq & \Psi_{1}^{-1}\left[\Psi _ { 2 } ^ { - 1 } \left(\Psi_{2}\left(\Psi_{1}\left(\left|x_{0}\right|\right)+\int_{0}^{\alpha(t)} \frac{g\left(\alpha^{-1}(s)\right)}{\alpha^{\prime}\left(\alpha^{-1}(s)\right)} d s\right)\right.\right. \\
& \left.\left.+\int_{0}^{\alpha(t)} \frac{f\left(\alpha^{-1}(s)\right)}{\alpha^{\prime}\left(\alpha^{-1}(s)\right)} d s\right)\right]
\end{aligned}
$$


for all $t<T_{6}$, where

$$
\begin{aligned}
& \Psi_{1}(r):=\int_{1}^{r} \frac{d t}{\Psi_{2}(t)}, \quad r>0, \\
& \Psi_{2}(r):=\int_{1}^{r} \frac{\Psi_{2}\left(\Psi_{1}^{-1}(s)\right) d s}{\Psi_{1}\left(\Psi_{1}^{-1}(s)\right)\left(\Psi_{1}^{-1}(s)\right)^{p}}, \quad r>0,
\end{aligned}
$$

and $T_{6}$ is the largest number such that

$$
\begin{aligned}
& \Psi_{2}\left(\Psi_{1}\left(\left|x_{0}\right|\right)+\int_{0}^{\alpha(t)} \frac{g\left(\alpha^{-1}(s)\right)}{\alpha^{\prime}\left(\alpha^{-1}(s)\right)} d s\right)+\int_{0}^{\alpha(t)} \frac{f\left(\alpha^{-1}(s)\right)}{\alpha^{\prime}\left(\alpha^{-1}(s)\right)} d s \leq \int_{1}^{\infty} \frac{\varphi_{2}\left(\Phi_{2}^{-1}(s)\right) d s}{\varphi_{1}\left(\Phi_{2}^{-1}(s)\right)\left(\Phi_{2}^{-1}(s)\right)^{p}}, \\
& \Psi_{2}^{-1}\left(\Psi_{2}\left(\Psi_{1}\left(\left|x_{0}\right|\right)+\int_{0}^{\alpha(t)} \frac{g\left(\alpha^{-1}(s)\right)}{\alpha^{\prime}\left(\alpha^{-1}(s)\right)} d s\right)+\int_{0}^{\alpha(t)} \frac{f\left(\alpha^{-1}(s)\right)}{\alpha^{\prime}\left(\alpha^{-1}(s)\right)} d s\right) \leq \int_{1}^{\infty} \frac{d t}{\varphi_{2}(t)} .
\end{aligned}
$$

Proof Integrating both sides of equation (3.88) from 0 to $t$, we get

$$
x(t)=x_{0}+\int_{0}^{t} H\left(s, x(\alpha(s)), \int_{0}^{s} K(\tau, x(\alpha(\tau))) d \tau\right) d s, \quad \forall t \in I .
$$

Using the conditions (3.89) and (3.90), from (3.92) we obtain

$$
\begin{aligned}
|x(t)| \leq & \left|x_{0}\right|+\int_{0}^{t} f(s) \varphi_{1}(|x(\alpha(s))|)\left(|x(\alpha(s))|+\int_{0}^{s} g(\tau) \varphi_{2}(|x(\alpha(\tau))|) d \tau\right)^{p} d s \\
\leq & \left|x_{0}\right|+\int_{0}^{\alpha(t)} \frac{f\left(\alpha^{-1}(s)\right)}{\alpha^{\prime}\left(\alpha^{-1}(s)\right)} \varphi_{1}(|x(s)|) \\
& \times\left(|x(s)|+\int_{0}^{s} \frac{g\left(\alpha^{-1}(\tau)\right)}{\alpha^{\prime}\left(\alpha^{-1}(\tau)\right)} \varphi_{2}(|x(\tau)|) d \tau\right)^{p} d s
\end{aligned}
$$

for all $t \in I$. Applying Theorem 4 to (3.93), we get the estimation (3.91). This completes the proof of Corollary 1.

\section{Competing interests}

The author declares that they have no competing interests.

\section{Acknowledgements}

The author is very grateful to the editor and the referees for their helpful comments and valuable suggestions. This research was supported by the National Natural Science Foundation of China (Project No. 11161018), Guangxi Natural Science Foundation (Project No. 0991265 and 2012GXNSFAA053009), Scientific Research Foundation of the Education Department of Guangxi Province of China (Project No. 201106LX599), and the Key Discipline of Applied Mathematics of Hechi University of China (200725).

Received: 19 February 2012 Accepted: 3 October 2012 Published: 17 October 2012

\section{References}

1. Gronwall, TH: Note on the derivatives with respect to a parameter of the solutions of a system of differential equations. Ann. Math. 20, 292-296 (1919). doi:10.2307/1967124

2. Bellman, R: The stability of solutions of linear differential equations. Duke Math. J. 10, 643-647 (1943). doi:10.1215/S0012-7094-43-01059-2

3. Lipovan, O: A retarded Gronwall-like inequality and its applications. J. Math. Anal. Appl. 252, 389-401 (2000). doi:10.1006/jmaa.2000.7085

4. Abdeldaim, A, Yakout, M: On some new integral inequalities of Gronwall-Bellman-Pachpatte type. Appl. Math. Comput. 217, 7887-7899 (2011). doi:10.1016/j.amc.2011.02.093

5. Agarwal, RP, Deng, S, Zhang, W: Generalization of a retarded Gronwall-like inequality and its applications. Appl. Math. Comput. 165, 599-612 (2005). doi:10.1016/j.amc.2004.04.067 
6. Agarwal, RP, Kim, YH, Sen, SK: New retarded integral inequalities with applications. J. Inequal. Appl. 2008, Article ID $908784(2008)$

7. Bihari, IA: A generalization of a lemma of Bellman and its application to uniqueness problem of differential equation. Acta Math. Acad. Sci. Hung. 7, 81-94 (1956). doi:10.1007/BF02022967

8. Pachpatte, BG: Inequalities for Differential and Integral Equations. Academic Press, London (1998)

9. Kim, YH: On some new integral inequalities for functions in one and two variables. Acta Math. Sin. 21, 423-434 (2005). doi:10.1007/s10114-004-0463-7

10. Cheung, WS: Some new nonlinear inequalities and applications to boundary value problems. Nonlinear Anal. 64, 2112-2128 (2006). doi:10.1016/j.na.2005.08.009

11. Wang, WS: A generalized retarded Gronwall-like inequality in two variables and applications to BVP. Appl. Math. Comput. 191, 144-154 (2007). doi:10.1016/j.amc.2007.02.099

12. Wang, WS, Shen, C: On a generalized retarded integral inequality with two variables. J. Inequal. Appl. 2008, Article ID $518646(2008)$

13. Wang, WS, Li, Z, Li, Y, Huang, Y: Nonlinear retarded integral inequalities with two variables and applications. J. Inequal. Appl. 2010, Article ID 240790 (2010)

14. Wang, WS, Luo, RC, Li, Z: A new nonlinear retarded integral inequality and its application. J. Inequal. Appl. 2010, Article ID 462163 (2010)

15. Wang, WS: Some generalized nonlinear retarded integral inequalities with applications. J. Inequal. Appl. 2012,31 (2012)

doi:10.1186/1029-242X-2012-236

Cite this article as: Wang: Some new generalized retarded nonlinear integral inequalities with iterated integrals and their applications. Journal of Inequalities and Applications 2012 2012:236.

\section{Submit your manuscript to a SpringerOpen ${ }^{\circ}$ journal and benefit from:}

- Convenient online submission

- Rigorous peer review

- Immediate publication on acceptance

- Open access: articles freely available online

- High visibility within the field

- Retaining the copyright to your article 